\title{
Penerapan Metode Prototype dalam Perancangan Aplikasi SIPINJAM Berbasis Website pada Credit Union Canaga Antutn
}

\author{
Petrus Yoko, Rabiatul Adwiya, Wahyu Nugraha \\ Program Studi Sistem Informasi, Fakultas Teknologi Informasi, Universitas Bina Sarana \\ Informatika Kota Pontianak, Pontianak, Indonesia \\ e-mail: petrusyoko@gmail.com, rabiatul.rba@bsi.ac.id, wahyu.whn@bsi.ac.id
}

\begin{abstract}
Abstrak
Credit Union (CU) Canaga Antutn bergerak dibidang jasa keuangan simpan pinjam. Canaga Antutn masih menggunakan teknik konvensional yaitu pencatatan menggunakan buku catatan untuk mengelola data simpan pinjam. Apabila terjadi kesalahan pada pencatatan transaksi simpan pinjam, maka akan sangat berpengaruh kepada laporan secara keseluruhan dan merugikan dua belah pihak baik anggota maupun perusahaan. Maka dari itu, dibuatlah aplikasi simpan pinjam berbasis website menggunakan model prototype. Observasi, wawancara dan studi pustaka dilakukan untuk pengumpulan data. Rancangan sistem informasi simpan pinjam menyediakan dua (2) level akses, yaitu admin tempat pelayanan dan bendahara. Admin tempat pelayanan mengelola data anggota, data simpanan, ambil simpanan, data pinjaman, data angsuran, mengakses laporan keanggotaan, laporan simpanan, laporan pinjaman, laporan angsuran dan laporan keuangan. Sedangkan bendahara mengelola data tempat pelayanan, data pengguna, mengakses laporan keanggotaan, laporan simpanan, laporan pinjaman, laporan angsuran dan laporan keuangan. Rancangan sistem ini diharapkan dapat membantu meningkatkan performa $\mathrm{CU}$ dalam pengolahan data simpan pinjam.
\end{abstract}

Kata Kunci: Credit Union, Metode Prototype, Sistem Informasi, Website,

\begin{abstract}
Credit Union (CU) Canaga Antutn is engaged in savings and loan financial services. Canaga Antutn still using the conventional techniques, namely recording using a notebook to manage savings and loan data. If an error occurs in the recording of savings and loan transactions, it will greatly affect the overall report and be detrimental to both parties both members and companies. Therefore, a website-based savings and loan applications are made using prototype models. Observation, interview and literature review being used to collect the data. Design of thrifts information system providing two level of access, that is every admin at service place and treasurer. Every admin at service place are able to administer the member's data, saving's data, withdraw saving's data, loan's data, instalment payment's data, accessing membership's report, saving's report, loan's report, instalment payment's report and financial statement. Meanwhile, the treasurer able to administer the place of service's data, user's data, accessing membership's report, saving's report, loan's report, instalment payment's report and financial statement. The design of this system is expected to improve the performance of $\mathrm{CU}$ in saving and loan data processing.
\end{abstract}

Keywords : Credit Union, Prototype Method, Information System, Website,

\section{Pendahuluan}

Perkembangan teknologi yang semakin tinggi menuntut kita untuk mengikuti perkembangan teknologi serta menggunakan teknologi. Namun, ada sebagian orang yang enggan mengikuti perkembangan zaman seperti perkembangan teknologi IT, maka mereka tidak akan mengerti kegunaan serta manfaat dari teknologi [1].

Komputer sangat populer digunakan sebagai alat bantu berbagai aktivitas, misalkan pada kegiatan administrasi bisnis bagi perusahaan. Komputer digunakan sebagai alat untuk 
menyimpan data, memanipulasi data serta menghasilkan informasi yang sesuai dengan kebutuhan. Permasalahan utama dari sarana kertas sebagai media pengolahan data menjadi suatu yang penting untuk diperhatikan dimana penggunaan kertas rentan akan terjadinya kehilangan data dan memakan banyak tempat untuk penyimpanan data. Permasalahan tersebut dapat diatasi oleh suatu aplikasi yang terintegrasi dengan basis data. Biaya operasional yang dikeluarkan juga lebih rendah apabila dihitung dalam skala tahunan dan bisa memaksimalkan semua potensi dari tenaga kerja yang dimiliki [2].

Credit Union (CU) merupakan suatu badan usaha yang keanggotaannya mencakup masyarakat setempat yang mengajukan pinjaman untuk modal usaha. Kondisi ekonomi saat ini yang tidak stabil, mengakibatkan sebagian masyarakat menyadari bahwa gaji yang dimiliki tidak selamanya bisa diandalkan sementara ekonomi yang semakin meningkat, sehingga didirikanlah Credit Union sebagai solusi dalam pemecahan masalah keuangan masyarakat [3].

CU Canaga Antutn dalam menjalankan tugas pokoknya saat ini masih menggunakan teknik konvensional yaitu pencatatan menggunakan alat tulis dan kertas-kertas dan kalkulator untuk mengelola data simpan pinjam anggota. Setiap transaksi simpan pinjam ditulis langsung di kartu simpan pinjam anggota (KSPA) yang kemudian salin kembali di Microsoft Excel. Apabila terjadi kesalahan pada pencatatan di KSPA, maka akan sangat berpengaruh kepada laporan secara keseluruhan dan merugikan ke dua belah pihak, yaitu anggota dan pihak perusahaan. Anggota juga diperbolehkan membayar angsuran pinjaman diberbagai tempat pelayanan yang disediakan, sehingga membuat admin yang melayani anggota tersebut harus memberikan informasi kepada tempat pelayanan asal dimana anggota tersebut melakukan registrasi dengan cara mengirim dokumen ke tempat asal tersebut. Setiap tempat pelayanan harus membuat rekapitulasi dan menyerahkan laporan keuangan kepada bendahara utama, kemudian bendahara utama dituntut untuk menggabungkan dan membuat laporan keuangan secara keseluruhan, hal ini di rasa tidak praktis dan menimbulkan masalah, karena apabila salah satu tempat pelayanan salah dalam membuat laporan, maka akan berdampak pada laporan keuangan secara keseluruhan.

Solusi dari permasalahan pengolahan data simpan pinjam pada Credit Union Canaga Antutn di Kabupaten Ketapang adalah mengubah teknik pengolahan data yang awalnya menerapkan teknik konvensional menjadi penerapan sistem informasi berbasis teknologi yang khusus mengolah data simpan pinjam sehingga membantu pihak Credit Union Canaga Antutn dalam pengolahan data simpan pinjam menjadi cepat, data disetiap tempat pelayanan saling terintegrasi dan dapat menyajikan dengan lebih mudah.

Berdasarkan uraian dari pendahuluan di atas, maka peneliti mengambil tema penelitian mengenai Perancangan Aplikasi SIPINJAM (Simpan Pinjam) Berbasis Website Pada Credit Union (CU) Canaga Antutn yang terletak di Kabupaten Ketapang, perancangan ini menggunakan metode Prototype dalam pengembangan perangkat lunaknya. Harapan dari rancangan sistem ini dapat membantu meningkatkan performa Credit Union (CU) Canaga Antutn di Kabupaten Ketapang dalam mengolah atau memproses transaksi simpan pinjam serta menghasilkan informasi atau laporan dengan cepat dan tepat sasaran. Selain itu laporan juga harus tepat guna sesuai dengan kebutuhan perusahaan.

\section{Metodologi Penelitian}

Metode penelitian digunakan sebagai suatu pedoman dalam menentukan langkah, gambaran, prosedur, waktu dan tempat pengambilan data. Pada penelitian ini peneliti menggunakan metode deskriptif. Metode penelitian deskriptif merupakan metode penelitian yang berupaya untuk menggambarkan dan menginterpretasi objek apa adanya sesuai dengan kondisi yang ada. Metode ini biasa disebut dengan metode non-eksperimen, karena tidak melakukan kontrol manipulasi terhadap variabel penelitian [4]. Metode penelitian deskriptif ini didukung oleh metode pengembangan perangkat lunak dengan model prototype dan teknik pengumpulan data.

\subsection{Metode Pengembangan Perangkat Lunak}

Bentuk dari prototype pada gambar 1 merupakan versi awal dari tahapan sebuah sistem software yang digunakan dalam mempresentasikan gambaran dari ide, eksperimen dari sebuah rancangan, mencari sebanyak mungkin masalah yang ada serta penyelesaian terhadap masalah tersebut [5]. Sistem dengan model prototype mengijinkan pengguna agar mengetahui seperti apa tahapan sistem dibuat sehingga sistem mampu beroperasi dengan baik. 
Metode prototype digunakan pada penelitian ini dimaksudkan untuk mendapatkan representasi dari pemodelan aplikasi yang akan dibuat. Rancangan aplikasi awal mulanya berbentuk mockup selanjutnya akan dievaluasi oleh pengguna. Setelah mockup dievaluasi pengguna tahap selanjutnya mockup menjadi bahan rujukan bagi pengembang software untuk merancang aplikasi.

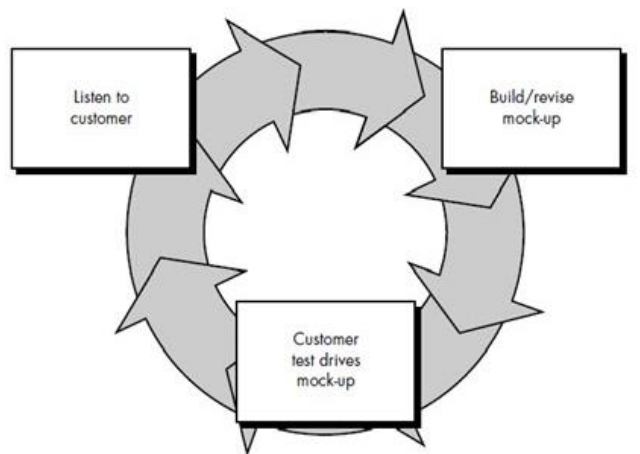

Gambar 1. Model Prototype oleh Khosrow-Pour [6].

\subsection{Teknik Pengumpulan Data}

Teknik pengumpulan data digunakan dalam pada tahap pengambilan data-data yang diperlukan, teknik ini diantaranya adalah wawancara, observasi dan studi pustaka. Observasi dilakukan dengan pengamatan langsung terhadap objek di CU Canaga Antutn yang beralamat di Desa Menyumbung, Kecamatan Hulu Sungai, Kabupaten Ketapang. Wawancara dilakukan langsung dengan bapak Leo Pede, SE. selaku ketua CU untuk memperoleh informasi yang lengkap dan benar. Melakukan studi pustaka dengan mencari referensi yang berkaitan dengan judul sebagai alat bantu dalam mencari informasi- informasi yang dibutuhkan.

\subsection{Desain LRS (Logical Record Structure)}

Rancangan logical record structure ditunjukkan pada gambar 2. Logical record structure (LRS) adalah visualisasi atau gambaran pola dari rekam data pada tabel yang terbentuk dari hasil pemodelan hubungan antar entitas beserta atributnya [7][8].

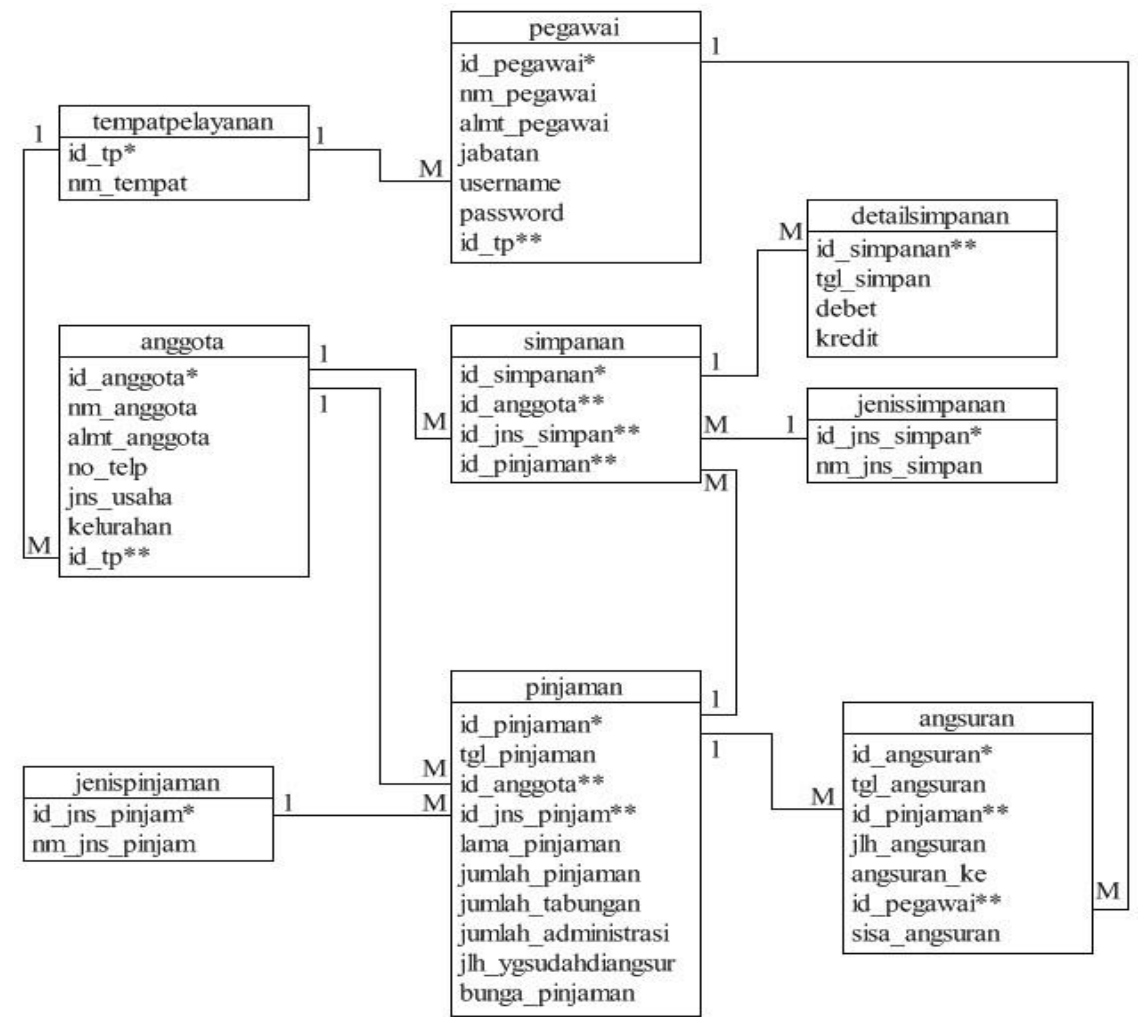

Gambar 2.Logical record structure (LRS) 


\subsection{Use Case Diagram}

Use case diagram dapat dilihat pada gambar 3. Use case diagram berfungsi untuk menjelaskan dalam bentuk gambar mengenai siapa saja aktor yang terlibat di sistem, fungsi apa saja yang bisa dilakukan oleh sistem, dan mendeskripsikan interaksi pengguna dengan sistem informasi [9].

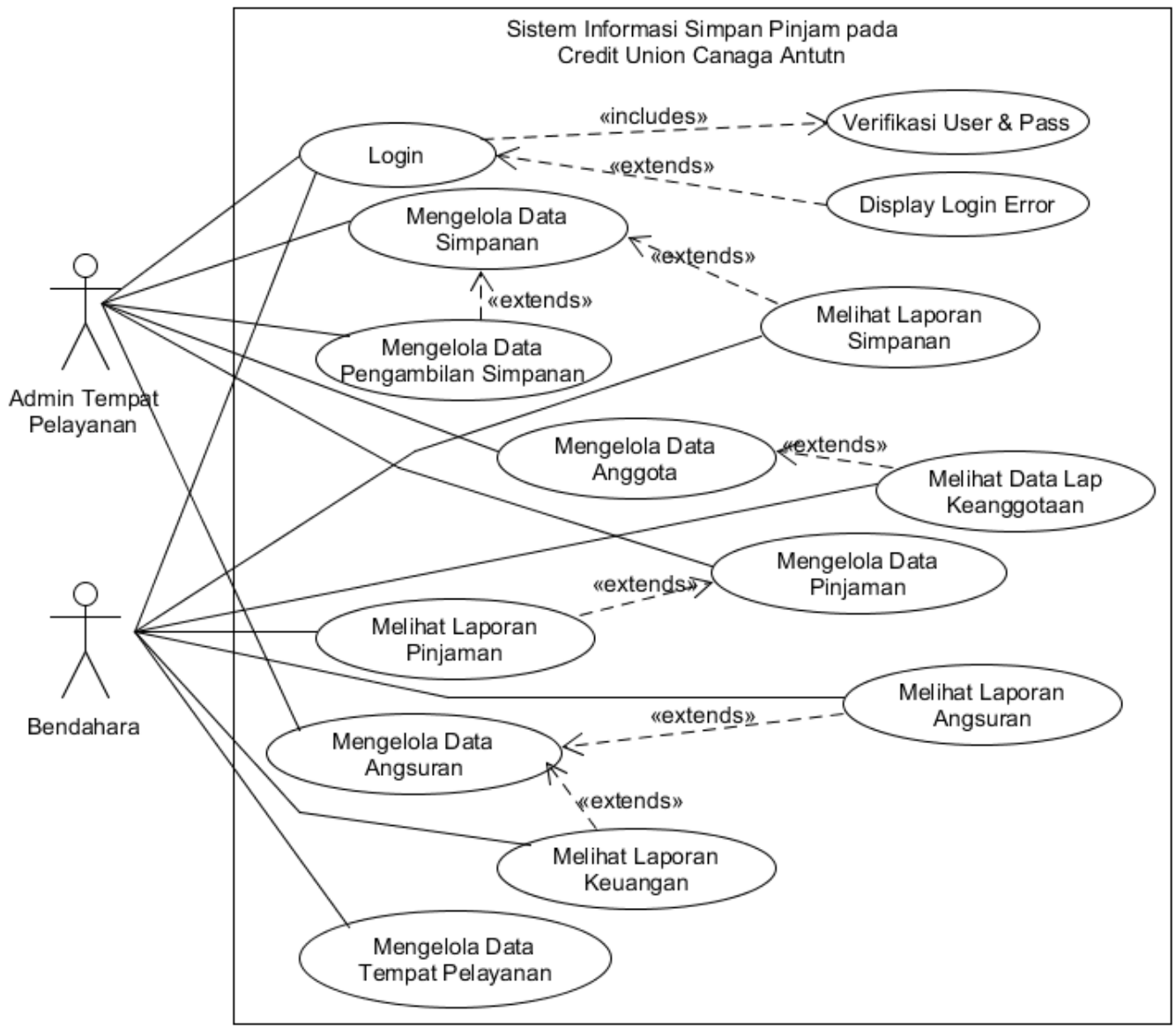

Gambar 3. Diagram Use Case

\section{Kajian Pustaka}

\subsection{Metode Prototype}

Model prototype ialah sebuah metode yang mengharuskan pengembang perangkat lunak membuat sebuah mockup berupa model aplikasi, sangat cocok pada kondisi dimana pengguna tidak bisa menyajikan informasi secara jelas mengenai kebutuhan yang sesuai dengan keinginannya [10]. Hasil dari model prototype berupa mockup yang akan menjadi rujukan model desain yang akan digunakan saat melatih, presentasi, penilaian sebuah desain, promosi atau keperluan lain [11].

\subsection{Credit Union}

Credit Union merupakan sebuah lembaga keuangan yang memiliki basis usaha simpan pinjam uang. Jadi, selain membantu mempercepat tumbuhnya dana dalam simpanan, credit union juga bisa dijadikan sumber dana sebagai modal dari usaha [12]. Credit Union adalah koperasi kredit yang bergerak dibidang usaha simpan pinjam dengan memberikan pinjaman dana kepada anggotanya untuk memenuhi kebutuhann hidup [13]. CU menganut prinsip kekeluargaan pada pelaksanaan kegiatannya sehingga tujuan utama CU dibentuk adalah demi meningkatkan kesejahteraan anggotanya.

\section{Hasil dan Pembahasan}

Pada bagian ini, akan dijelaskan hasil dari penelitian dan pembahasan yang komprehensif baik dari analisa kebutuhan hingga desain tampilan dari website. Pada analisa 
kebutuhan sisem akan dijabarkan kebutuhan fungsional dan non fungsional dari sistem. Sedangkan pada bagian desain tampilan program web, akan menggambarkan hasil dari rancangan user interface atau antarmuka dari sistem informasi. Rancangan ini terdiri dari dua (2) level akses, yaitu admin tempat pelayanan dan bendahara.

\subsection{Analisis Kebutuhan}

Rancangan aplikasi SIPINJAM ini memiliki dua (2) kebutuhan sistem, yaitu kebutuhan fungsional dan non-fungsional. Kebutuhan fungsional sistem terdiri dari beberapa fungsi utama yang saling berkaitan dan saling mendukung satu sama lain. Sedangkan kebutuhan non fungsional sistem memiliki fungsi sebagai sarana pendukung agar kelancaran dari fungsi utama beroperasi sesuai dengan harapan.

\subsubsection{Analisa Kebutuhan Fungsional}

Dalam rancangan aplikasi SIPINJAM terdiri dari dua (2) akses, yaitu admin setiap tempat pelayanan dan bendahara. Adapun kegiatan atau scenario use case yang dilakukan admin dan bendahara adalah

1. Skenario Kebutuhan Bagian Admin: login, mengelola data anggota, mengelola data simpanan, mengelola ambil pinjaman, mengelola data pinjaman, mengelola data angsuran, melihat laporan keanggotaan, laporan simpanan, laporan pinjaman, laporan angsuran, laporan keuangan dan melakukan logout

2. Skenario Kebutuhan Bagian Bendahara: login, mengelola data tempat pelayanan, melihat laporan keanggotaan, laporan simpanan, laporan pinjaman, laporan angsuran, laporan keuangan dan melakukan logout.

\subsubsection{Analisa Kebutuhan Non Fungsional}

Kebutuhan non-fungsional merupakan kebutuhan di luar kebutuhan fungsional yaitu meliputi kebutuhan akan spesifikasi hardware dan kebutuhan software yang sangat mempengaruhi beroperasinya website dengan jaringan local. Adapun kebutuhan fungsional tersebut meliputi.

\section{Hardware}

Spesifikasi perangkat keras (hardware) minimum yang dibutuhkan untuk aplikasi SIPINJAM ini adalah.

$\begin{array}{ll}\text { Processor } & : 1.5 \mathrm{GHz} \text { Dual core } \\ \text { Memory (RAM) } & : 2 \mathrm{~GB} \text { DDR3 } \\ \text { Hard disk } & : 120 \mathrm{~GB} \\ \text { Monitor } & : \text { Resolusi Layar (1366 x 768) } \\ \text { Keyboard } & : \text { QWERTY (86 keys) } \\ \text { Mouse } & \text { : Optical } \\ \text { Printer } & \text { : Ink Jet }\end{array}$

2. Software

Spesifikasi perangkat lunak (software) minimum untuk menggunakan maupun merancang sistem ini sebagai berikut:
Sistem Operasi
Xampp
: Windows 7
: Terdiri dari beberapa komponen diantaranya:
- Xampp Server, Versi Xampp Control Panel v.3.2.2
- Apache Server versi 2.4.3.
- Aplikasi MySQL Server Versi 5.1.36
- Aplikasi PHP Versi 5.3.0
Bahasa pemograman
: PHP framework Codeigniter, HTML, CSS, CSS framework
Text Editor
Bootstraps, jQuery dan javascript
Database
: Visual Studio Code.
Web browser
: Mysql
: Google Chrome, Mozilla Firefox, Edge, Opera, UC Browser.

\subsection{Tampilan Sistem untuk Admin Tempat Pelayanan}

Berikut ini merupakan tampilan dari hasil rancangan aplikasi website. Desain tampilan yang ditampilkan berikut ini hanya berfokus pada proses bisnis dari sistem dan mengacu kepada rancangan desain dari use case diagram pada gambar 3 . Adapun desain halaman web 
untuk level admin diataranya tampilan halaman mengolah data simpanan, data pengambilan simpanan pada, data anggota, data pinjaman, dan data angsuran. Tampilan laporan akan ditampilkan pada sub bab berikutnya karena laporan yang diakses oleh admin juga bisa diakses oleh bagian bendahara.

Tampilan halaman untuk mengelola data simpanan dapat dilihat pada gambar 4 . Halaman ini digunakan Admin untuk mengelola semua data simpanan seluruh anggota diantaranya melihat saldo simpanan, melihat riwayat setoran simpanan, dan mencatat setoran simpanan yang masuk atau diterima.

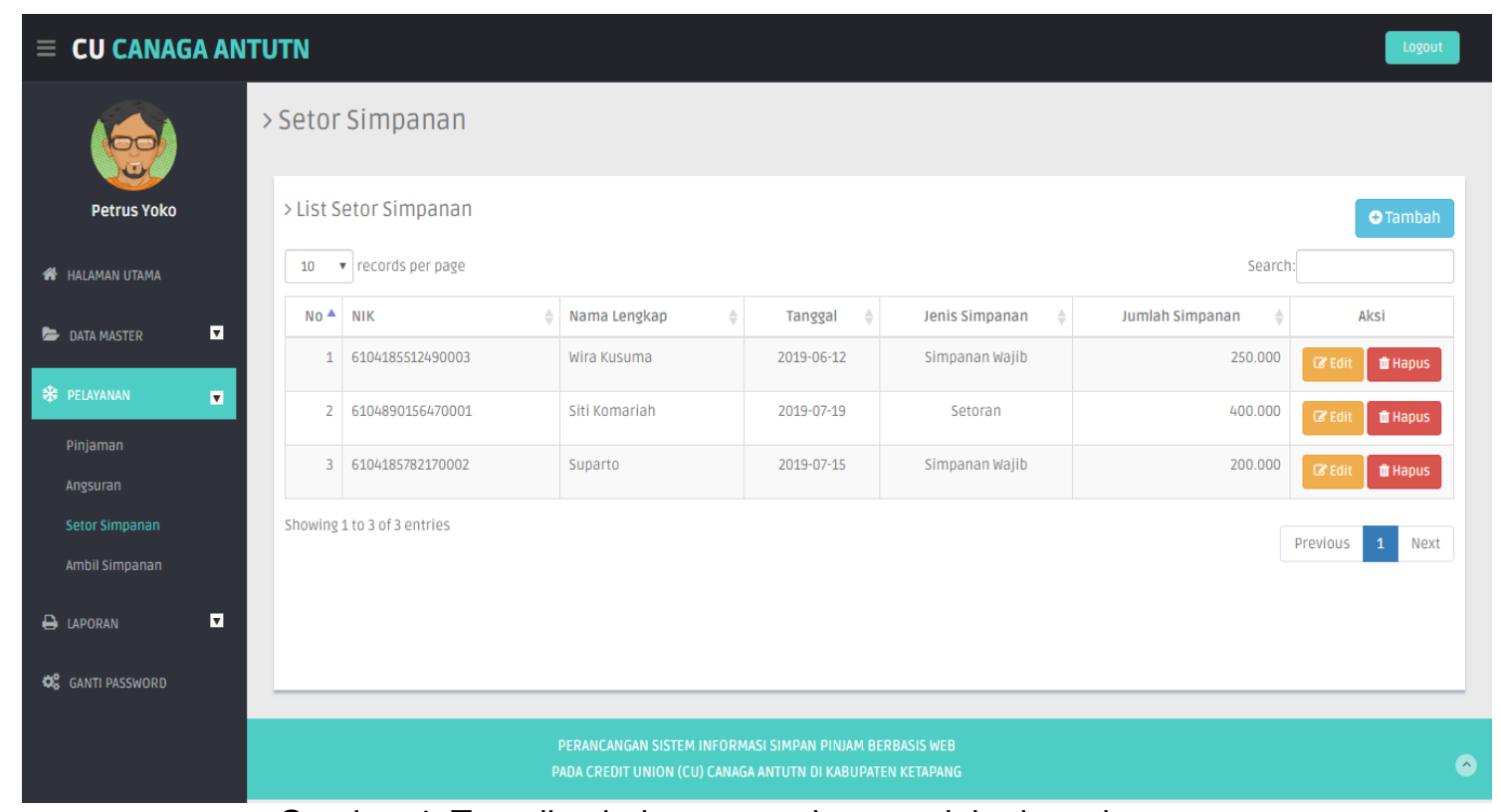

Gambar 4. Tampilan halaman untuk mengelola data simpanan

Tampilan halaman untuk mengelola data pengambilan simpanan dapat dilihat pada gambar 5. Halaman ini digunakan Admin untuk mengolah data pengambilan simpanan seluruh anggota seperti mencatat data pengambilan simpanan dan melihat riwayat pengambilan simpanan.

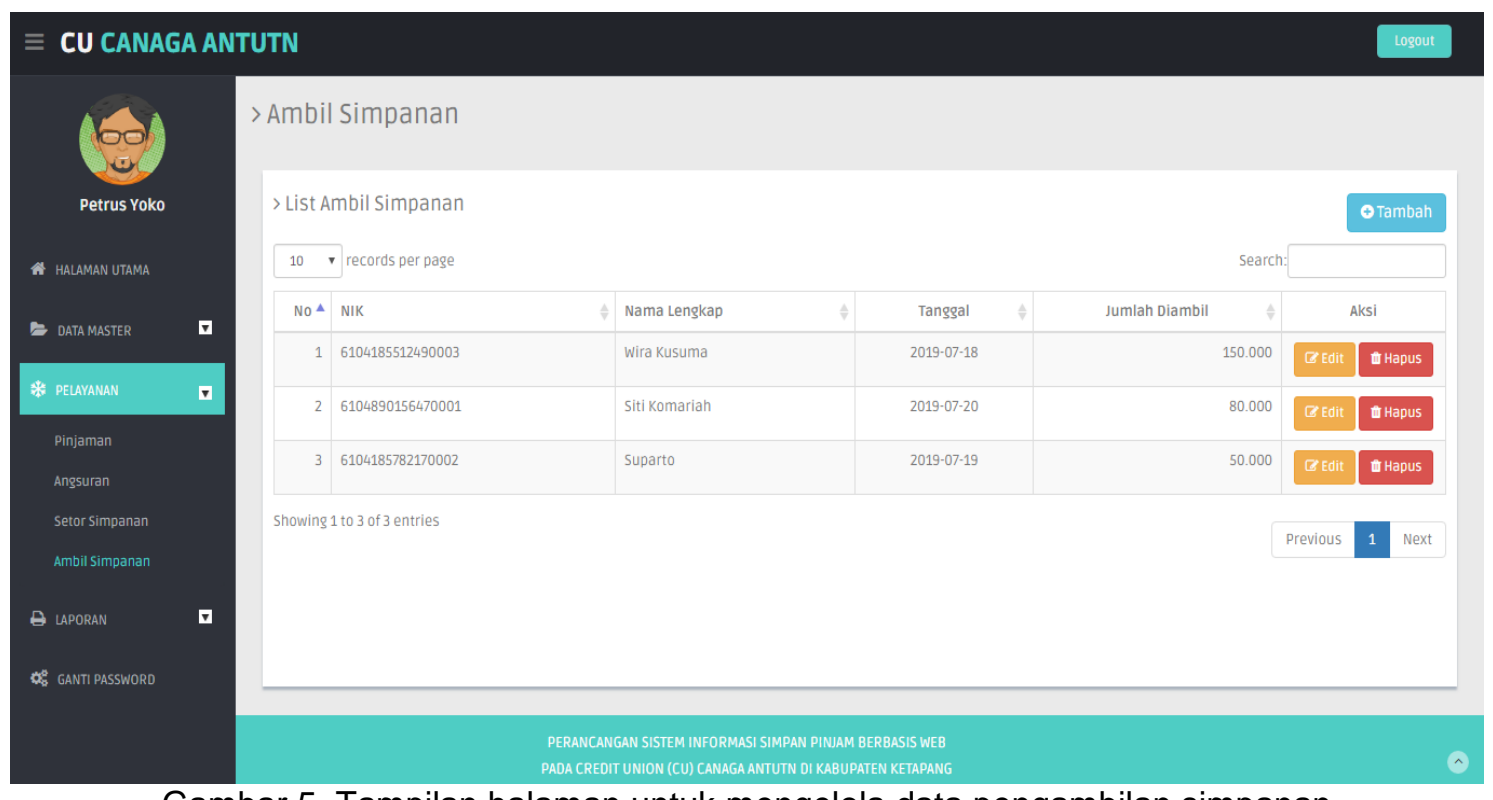

Gambar 5. Tampilan halaman untuk mengelola data pengambilan simpanan 
Tampilan halaman mengelola data anggota dapat dilihat pada gambar 6. Halaman ini digunakan Admin untuk mengolah seluruh data anggota diantaranya melihat data anggota, menambahkan data anggota baru, mengubah profile data anggota, dan menghapus data anggota yang sudah tidak menjadi anggota CU.

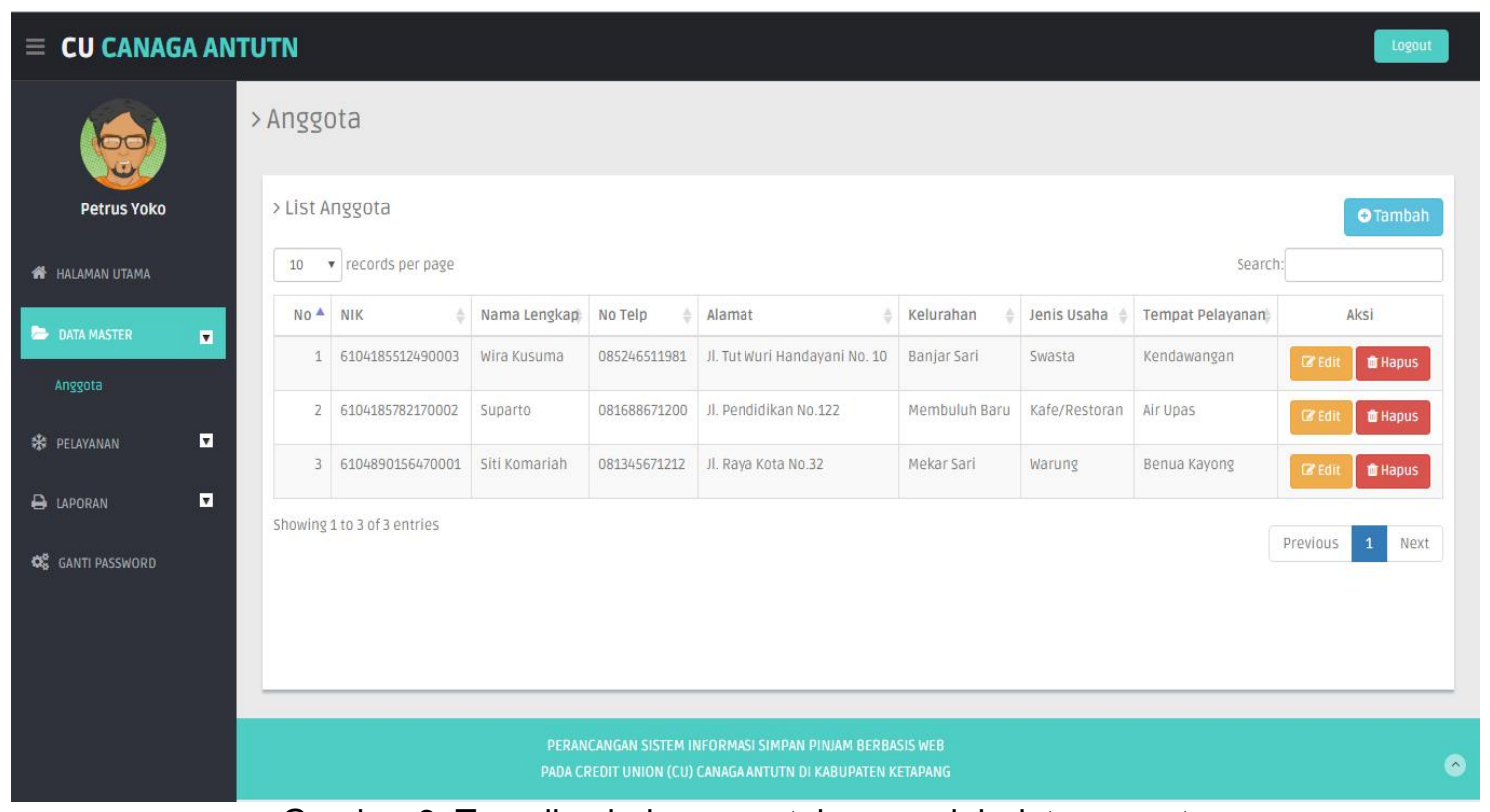

Gambar 6. Tampilan halaman untuk mengolah data anggota

Tampilan halaman mengelola data pinjaman dapat dilihat pada gambar 7. Halaman ini digunakan Admin tempat pelayanan untuk mengolah seluruh data pinjaman anggota seperti melihat data pinjaman anggota, mengubah atau menghapus jika terjadi kesalahan pada pencatatan pinjaman, melihat riwayat pinjaman anggota dan mencatat data peminjaman yang dilakukan oleh anggota.

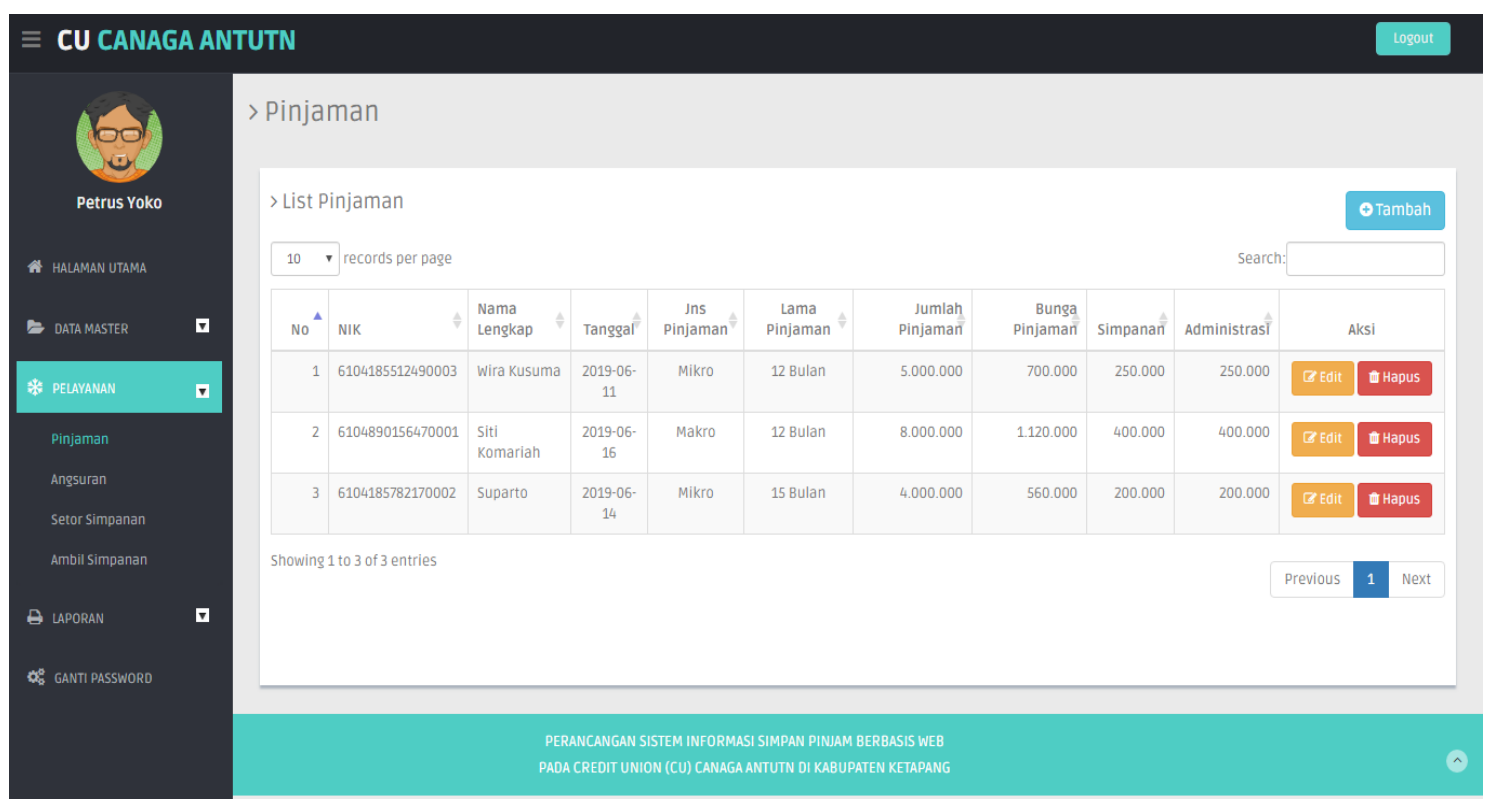

Gambar 7. Tampilan halaman untuk mengolah data pinjaman

Tampilan halaman untuk mengelola angsuran pinjaman dapat dilihat pada gambar 8 . Halaman ini digunakan Admin untuk mengolah seluruh data setoran angsuran dari anggota yang melakukan pinjaman. Halaman ini memiliki fitur seperti mencatat setoran untuk 
pembayaran angsuran pinjaman, melihat riwayat cicilan setoran anggota, melihat masa waktu setoran, sisa angsuran dan jumlah pinjaman anggota.

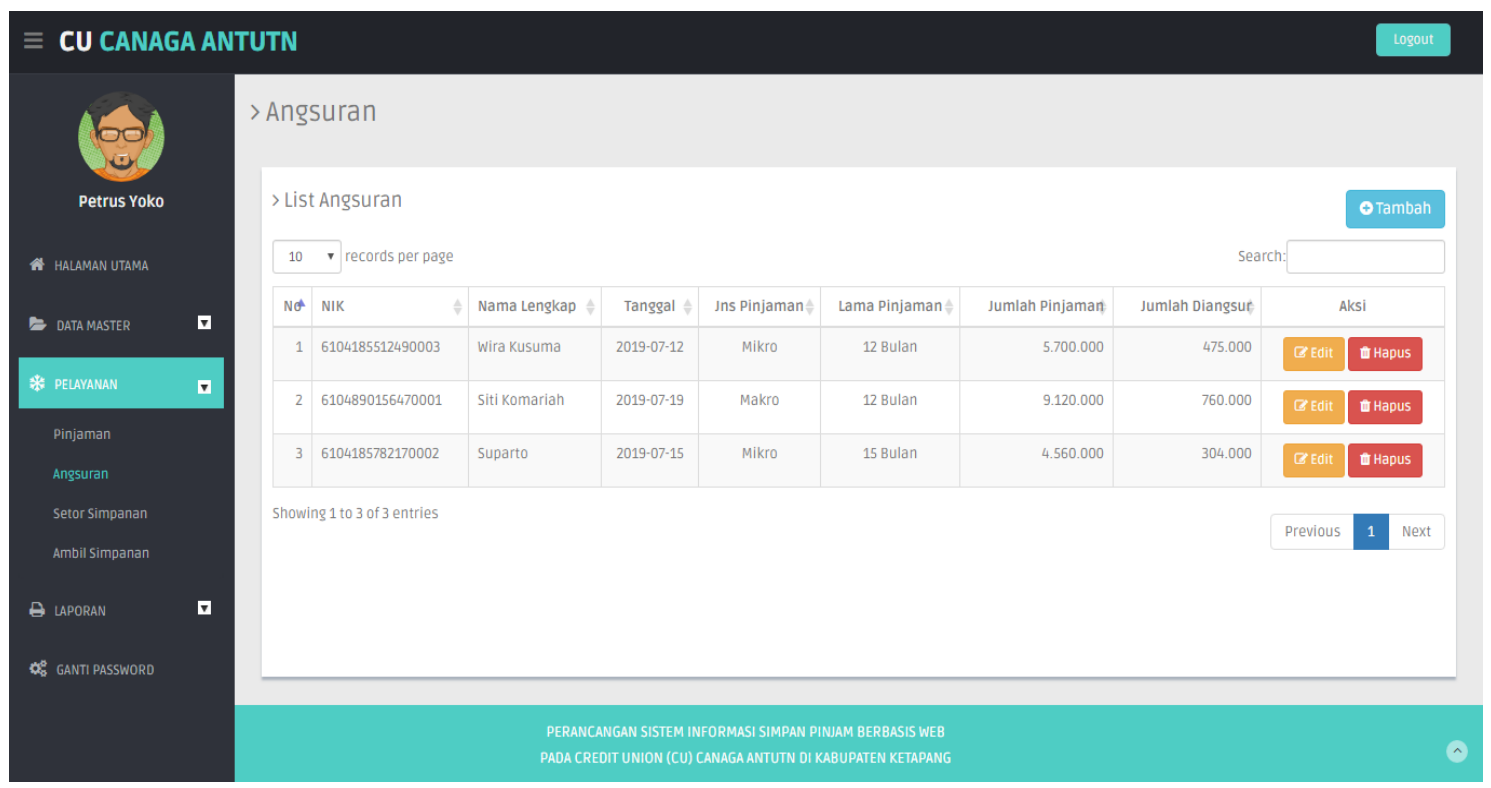

Gambar 8. Tampilan halaman untuk mengolah data angsuran pinjaman

\subsection{Tampilan Sistem untuk Bendahara}

Berikut ini merupakan tampilan dari hasil rancangan aplikasi website untuk level bendara. Desain tampilan yang ditampilkan hanya berfokus pada proses bisnis dari sistem saja dan mengacu kepada desain dari use case diagram pada gambar 3. Desain halaman web untuk level bendahara diataranya tampilan halaman mengelola data tempat pelayanan, laporan simpanan, laporan keanggotaan, laporan pinjaman, laporan angsuran, dan laporan keuangan.

Tampilan halaman untuk mengelola data halaman mengolah data tempat pelayanan dapat dilihat pada gambar 9. Halaman ini digunakan oleh Bendahara untuk mengelola semua data tempat pelayanan $\mathrm{CU}$ atau data cabang dari CU semua wilayah.

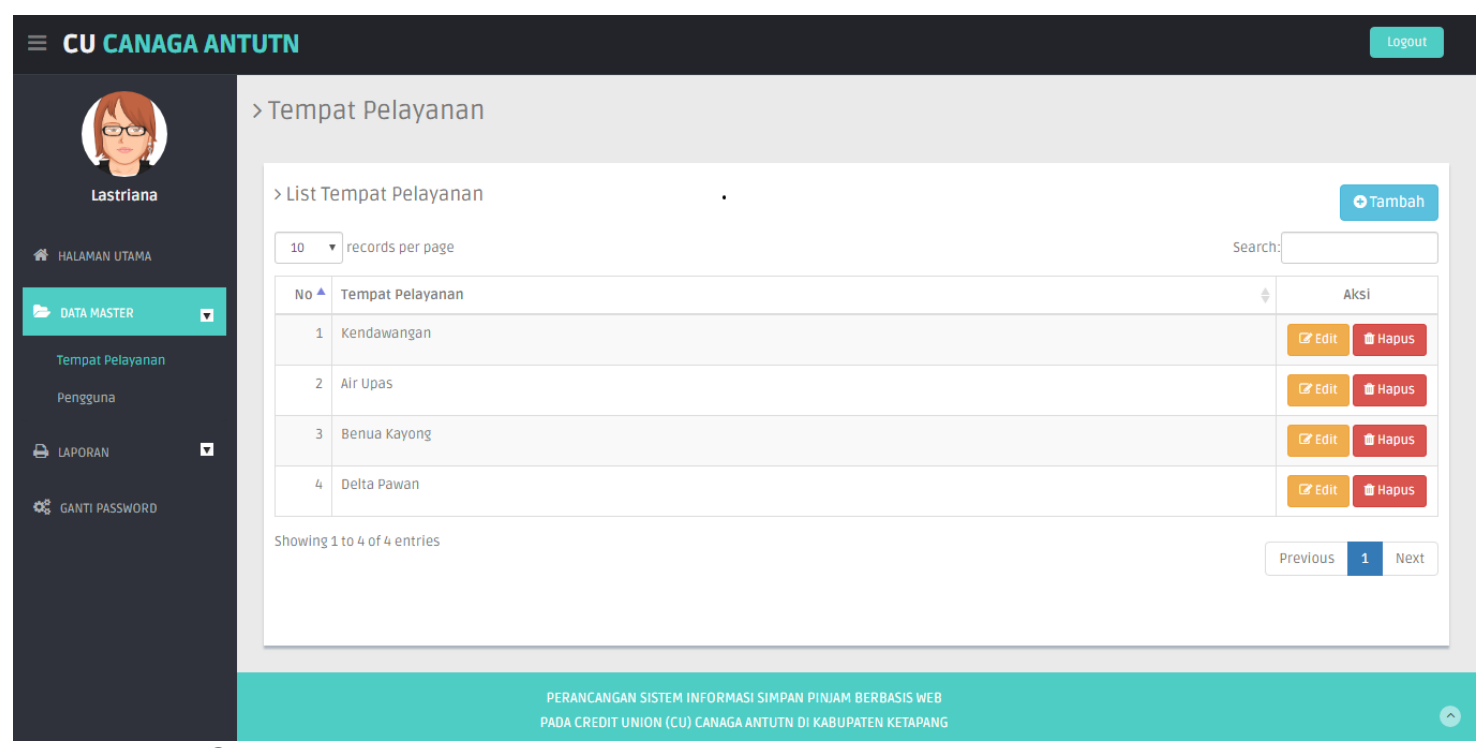

Gambar 9. Tampilan halaman untuk mengolah data tempat pelayanan

Pada level admin halaman laporan yang tidak ditampilkan pada subbab sebelumnya ditampilkan pada sub bab ini. Karena ada beberapa laporan seperti laporan simpanan, laporan keanggotaan, laporan pinjaman, laporan angsuran dan laporan keuangan juga bisa diakses oleh bendahara. Berikut ini adalah beberapa tampilan untuk melihat semua jenis laporan. 
Tampilan halaman untuk melihat laporan simpanan dapat dilihat pada gambar 10 . Halaman ini digunakan oleh Admin maupun Bendahara untuk melihat ataupun mencetak semua laporan dari simpanan anggota. Laporan simpanan dapat dilihat berdasarkan nomor induk kependudukan dari anggota disertai dengan tanggal.

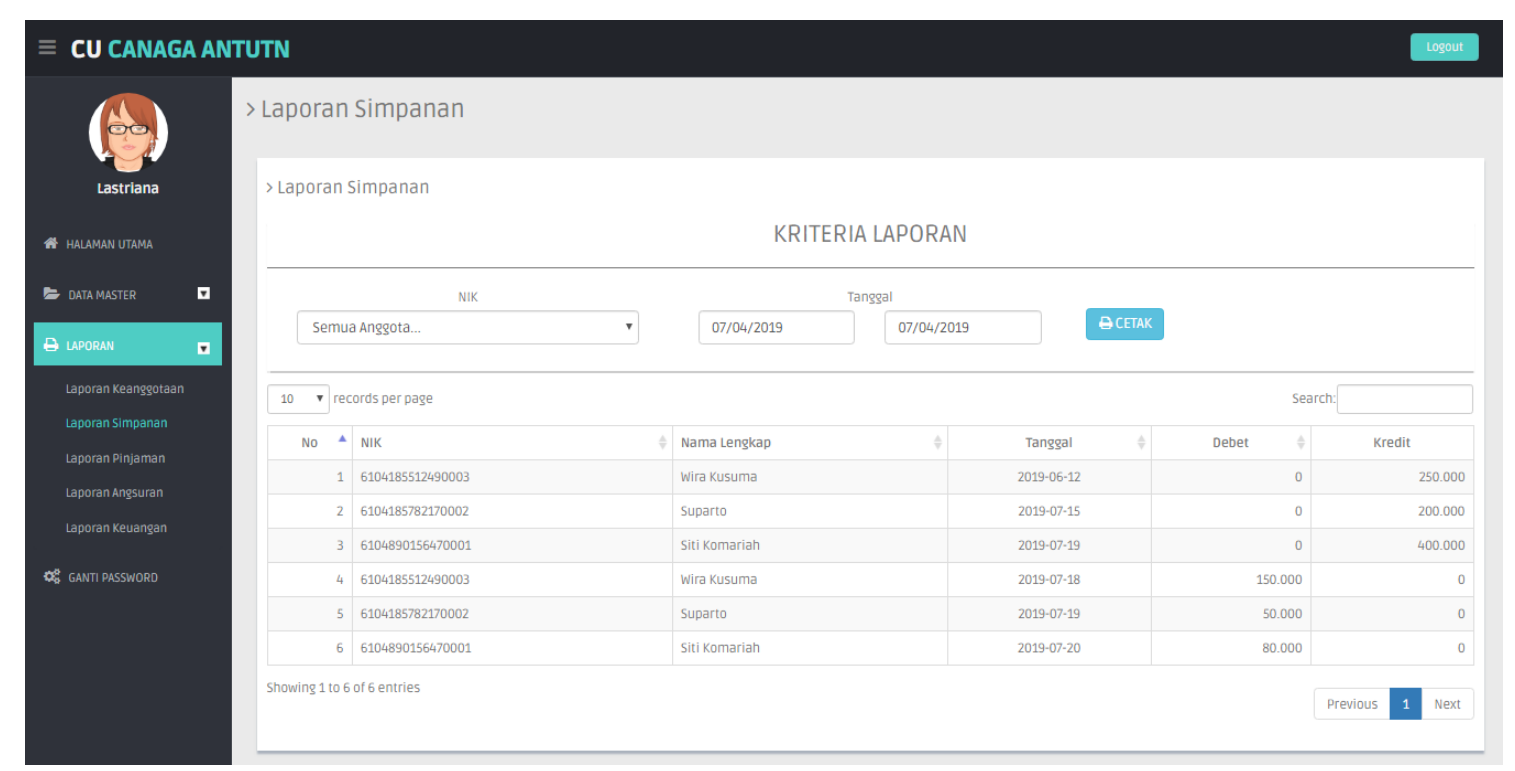

Gambar 10. Tampilan halaman laporan simpanan

Tampilan halaman untuk melihat laporan keanggotaan dilihat pada gambar 11 . Halaman ini digunakan oleh Admin maupun Bendahara untuk melihat ataupun mencetak semua anggota yang terdaftar. Laporan anggota dapat dilihat berdasarkan nomor induk kependudukan dari anggota atau melakukan pencarian berdasarkan nama, alamat, dan nomor telepon.

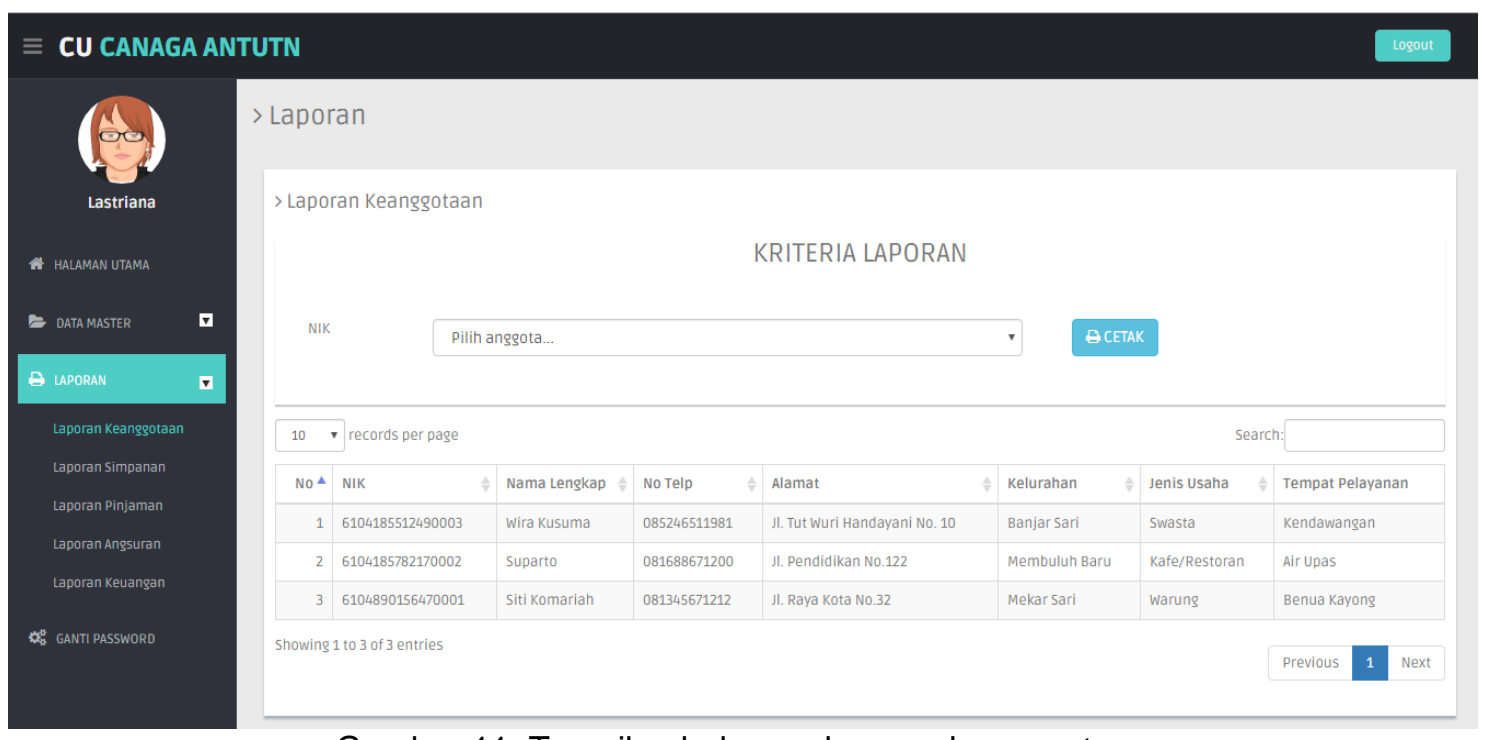

Gambar 11. Tampilan halaman laporan keanggotaan

Tampilan halaman untuk melihat laporan pinjaman anggora CU dapat dilihat pada gambar 12. Halaman ini digunakan oleh Admin maupun Bendahara untuk melihat ataupun mencetak semua pinjaman anggota. Laporan pinjaman anggota dapat dilihat berdasarkan nomor induk kependudukan dari anggota disertai dengan tanggal atau melakukan pencarian berdasarkan nama. 


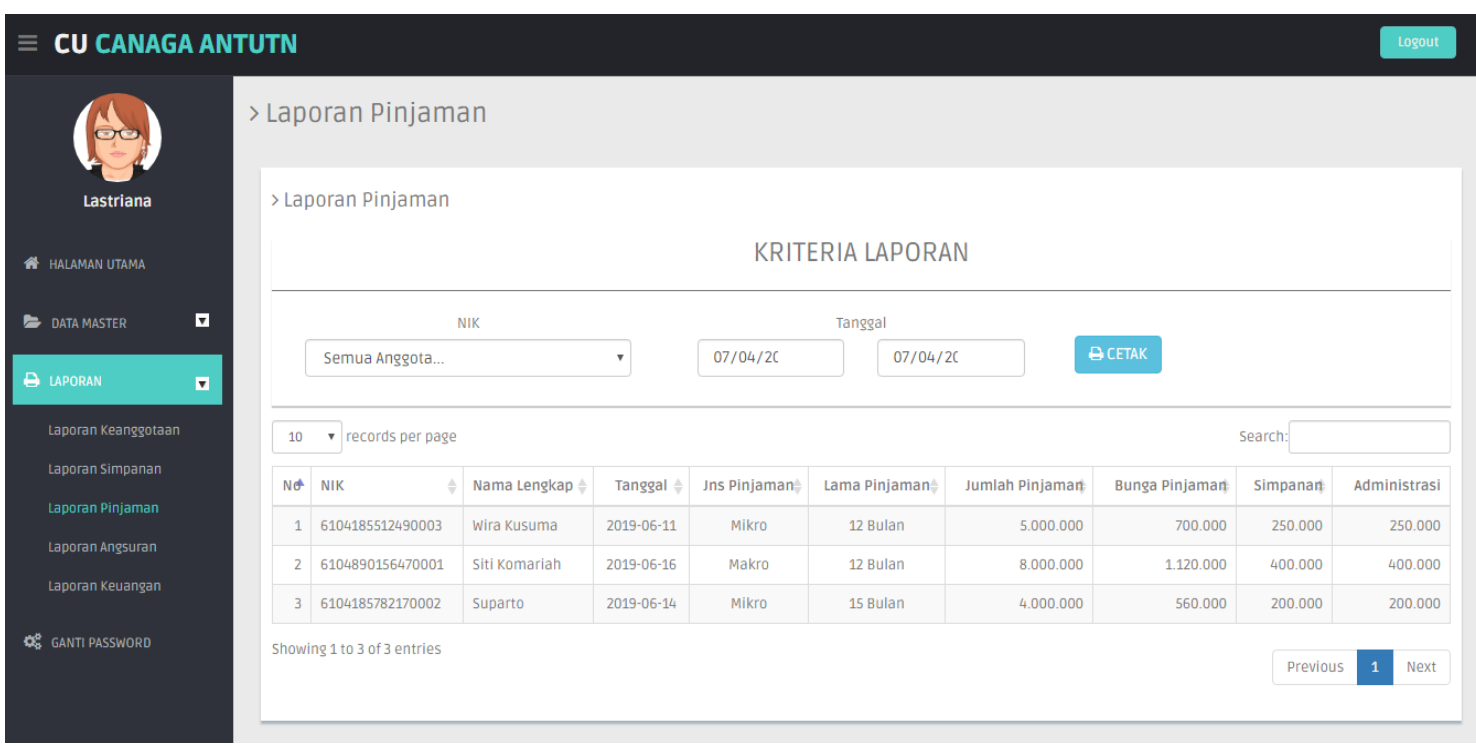

Gambar 12. Tampilan halaman laporan pinjaman

Tampilan halaman untuk melihat laporan pembayaran angsuran anggora CU dapat dilihat pada gambar 13. Halaman ini digunakan Admin maupun Bendahara untuk melihat ataupun mencetak semua data angsuran anggota. Laporan angsuran anggota dapat dilihat berdasarkan nomor induk kependudukan dari anggota disertai dengan tanggal atau melakukan pencarian berdasarkan nama.

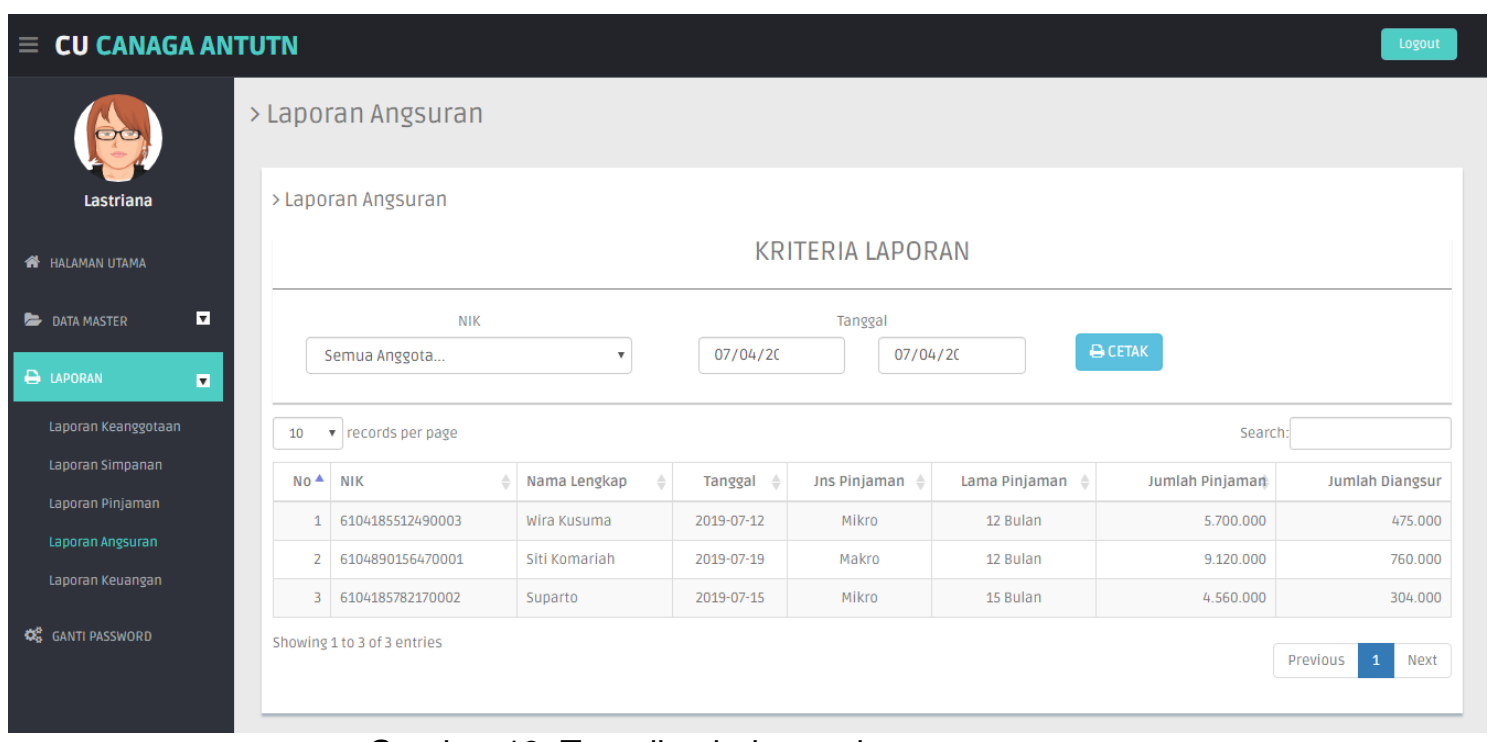

Gambar 13. Tampilan halaman laporan angsuran

Tampilan halaman untuk melihat laporan keuangan CU dapat dilihat pada gambar 14 Halaman ini digunakan oleh Admin maupun Bendahara untuk melihat ataupun mencetak semua laporan keuangan. Laporan keuangan dapat dilihat berdasarkan tanggal. 


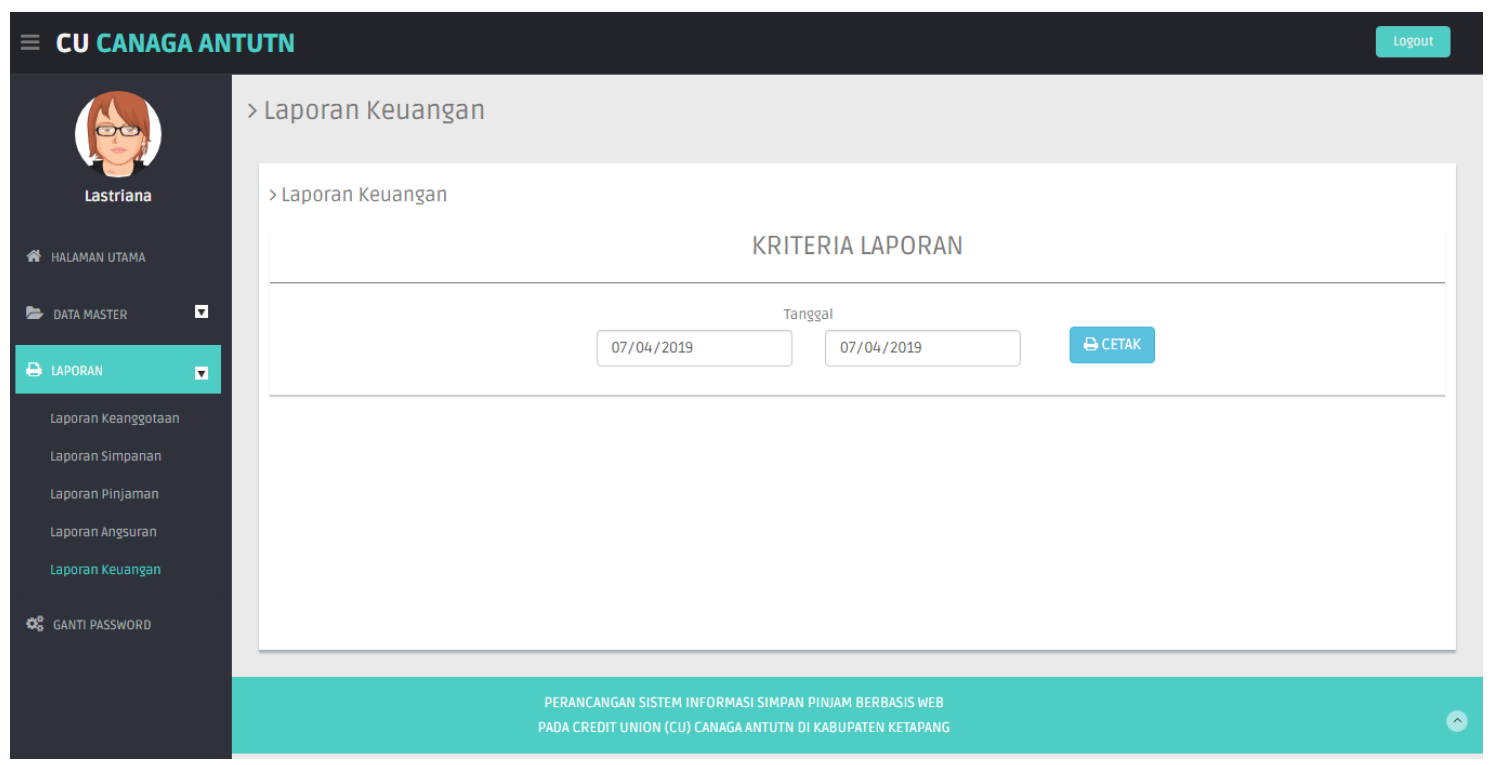

Gambar 14. Tampilan halaman laporan keuangan

\section{Kesimpulan}

Berdasarkan hasil penelitian mengenai rancangan aplikasi SIPINJAM yang telah dirancang, peneliti mengambil kesimpulan bahwa aplikasi ini dapat berjalan dengan baik sesuai yang harapkan sehingga dapat membantu meningkatkan performa CU Canaga Antutn dalam pengolahan data simpan pinjam seperti mengelola data anggota, simpanan, pinjaman, angsuran dan lain sebagainya. Semua rekaman data transaksi bisnis tersimpan rapi dan terstruktur menggunakan basis data dan dapat digunakan kembali serta mudah dalam melakukan pencarian data.

Sistem informasi simpan pinjam ini dapat dievaluasi dan dikembangkan lebih lanjut agar sistem ini menjadi jauh lebih baik. Contohnya seperti membuat desain tampilan (user interface) agar menjadi lebih menarik dan ramah dengan pengguna (user friendly), sistem informasi simpan pinjam dikembangkan juga menjadi aplikasi berbasis mobile, sehingga pengguna sistem (user) dapat mengakses melalui media smartphone.

\section{Daftar Pustaka}

[1] R. Adwiya, "Perancanaan Strategis SI/TI Menggunakan Four Stage Model Pada Dinas Pendidikan Kabupaten Kubu Raya Kalimantan Barat," Khatulistiwa Inform., vol. 3, no. 2, pp. 180-198, 2015.

[2] D. O. Sihombing, W. Nugraha, and F. Amdani, "Aplikasi Pengelolaan Data Order Mkios Berbasis Web Pada TDC PT. Telesindo Shop Pontianak," Simp. Nas. IImu Pengetah. dan Teknol. 2016, vol. 1, no. 1, pp. 129-137, 2016.

[3] M. I. Saputro and T. Mardiana, "Agen Cerdas Untuk Penentuan Kelayakan Pemberian Kredit Koperasi Simpan Pinjam," Tek. Komput., vol. 1, no. 2, pp. 245-252, 2015.

[4] M. Hariwijaya, Metodologi dan Teknik Penulisan Skripsi, Tesis \& Disertasi (untuk ilmu sosial dan humaniora), Cet. 2. Yogyakarta: Parama Ilmu, 2017.

[5] I. Sommerville, Software Engineering, 9th ed. Boston: Addison-Wesley, 2007.

[6] M. Khosrow-Pour, Encyclopedia of Information Science and Technology. Hershey, PA, USA: IGI Global Publishing, 2005.

[7] A. Junaidi, "Dashboard Sistem Informasi Support Maintenance (Studi Kasus: PT Polyta Global Mandiri)," IJCIT (Indonesian J. Comput. Inf. Technol. ), vol. 1, no. 1, pp. 17-26, 2016.

[8] Riyanto, Migrasi Microsoft SQL server dengan Postgresql. Jakarta: PT Elex Media Komputindo, 2005.

[9] U. Rusmawan, Teknik Penulisan Tugas Akhir dan Skripsi Pemrograman. Jakarta: Elex Media Komputindo, 2019. 
[10] Yurindra, Software Engineering, Cet 1. Yogyakarta: Deepublish, 2017.

[11] R. A. Sukamto and M. Shalahuddin, Rekayasa Perangkat Lunak: Terstruktur dan berorientasi objek. Bandung: Informatika, 2015.

[12] B. Herprasetyo, Berani Utang Untuk Investasi Pasti Untung! Blitar: Adora Media, 2013.

[13] Sunarmi, T. M. Lubis, and K. S. M. Gultom, "Pelaksanaan Prinsip Pemberian Pinjaman yang Sehat dalam Penyaluran Pinjaman oleh Koperasi Kredit CU Mandiri Tebing Tinggi (Studi Implementasi Terhadap Pasal 19 Ayat (2) Peraturan Pemerintah Nomor 9 Tahun 1995 Tentang Pelaksanaan Kegiatan Usaha Simpan Pinj," Transpar. (e-journal Econ. law), vol. 1, no. 1, 2018. 